ment are present in the cytoplasm of the parasite, ${ }^{3}$ whereas with the other three species, in all forms larger than the ring forms, 2050 individual grains can be seen. It does happen occasionally, but not often, that in $P$. vivax only ring forms may be found, but if the species is mistaken for $P$. falciparum it is of no importance. There is something to be said for advising pathologists to send all malaria films to specialists for confirming species diagnosis, even after treatment has been started.

Quite recently we were sent films of a patient who had never left the shores of the United Kingdom. He had had a blood transfusion," and died several weeks later from what was believed to be malignant malaria and black-water fever. It was in fact a human and fatal case of Babesia (Piroplasma divergens), and the blood transfusion had no part in the infection. The so-called blackwater fever was in fact redwater fever. The parasites so very closely resemble morphologically the ring forms of $\boldsymbol{P}$. falciparum that only an experienced worker could be expected to make the differentiation. Although this is the first case of human Babesia ever to be reported in the United Kingdom and only the third anywhere in the world, it does, I think, justify the above remarks. Incidentally this patient, as with the other two known cases, one in Yugoslavia ${ }^{5}$ and the other in California, ${ }^{6}$ had had a splenectomy. I would add that the diagnosis of piroplasmosis was confirmed by Professor P. C. C. Garnham.

All the piroplasmata of cattle, horses, and other animals were at first placed in the genus Piroplasma or Babesia. Piroplasmosis is endemic among cattle, sheep, and rodents in many parts of the United Kingdom, and, although the number of people who have had a splenectomy is small, it nevertheless may be of some importance, especially among farmworkers and veterinary surgeons.-I am, etc.,

Malaria Reference Laboratory, P. G. Shute. Horton Hospital, Surrey.

REFERENCES

- Maegraith, B. G., Exotic Diseases in Practice, 1965. London. 1966, 60, 412 .

- Shute, P. G., Lancet, 1965, 2, 1232.

Grant, D. B., Perinpanayagam, M. S., Shute, P. G., and Zeitlin, R. A., Lancet, 1960, 2, 469.
Skrabalo, Z., and Deanovic, Z., Docum. Med. geogr, Z., and Deanovic, Z., Doc geogr. trop. (Amst.), 1957, 9, 11.
Brann, E., and Condit, P., U.S. Dept. Health,
Education, and Welfare, 1967, No. 1, 8.

Education, and Welfare, 1967, No. 1, 8. Proto-
Garnham, P. C. C., and Bray, R. S., f. Protozool., 1959, 6, 352 .

\section{Diverticulosis and Diverticulitis}

SIR,-May we be allowed to comment on Dr. E. Goulston's letter (11 November 1967, p. 359) ? A statement in inverted commas is attributed to us (2 July 1966, p. 50) which we never made. Our letter stressed that diverticulitis does not occur in African negroes living tribally on unrefined grains, and was also rare in United States negroes when they lived on the same class of foodstuff. Dr. Goulston, writing from Addis Ababa (6 May 1967, p. 378), stated that no case of diverticulitis had ever been reported from Ethiopia either, but that diverticulosis had been seen. One of us replied (22 July 1967 , p. 243), with supporting barium-meal studies, that this is exactly what would be expected with a changing diet, diverticulosis being regarded as the precursor condition and Mr. N. S. Painter supported us (12
August 1967, p. 434). We see no new argument in Dr. Goulston's latest letter.

With regard to Dr. S. N. Salem's letter (23 September 1967, p. 800) pointing out the absence of diverticulitis in Kuwaitis, though the diet is frequently refined, this appears to present no difficulty. It has been demonstrated that even in Westernized countries diverticulitis is rare under the age of 40 (23 September 1967 , p. 762), showing that a very long period of time is needed to produce the condition, and it is therefore too early yet to assess the colonic consequences of the change in the Kuwaitis' diet, which are relatively recent. We are confident that cases of diverticulitis will start up both in Kuwait and in Addis Ababa during the next decade or so, probably earlier.

With regard to the paper by Dr. Manousos and others (23 September 1967, p. 762) showing intestinal transit times in normal and diverticulosis subjects, we see no difficulty here either. These subjects were all from our own population, which even 25 years ago was shown by J. N. Morris ${ }^{1}$ to be taking regular aperients in $60 \%$ of its numbers, and we note that over $90 \%$ of the "normals" in the present paper retained food in the gut three, four, five, or even more days after its ingestion. We can well believe that the transit times in diverticulosis subjects may be shorter than these times, since we believe that the condition arises from the efforts of the colon in certain people to overcome just this type of delay, but we equally believe that all these transit times are very different from the natural transit time. We plan to do a series of comparable studies in Africans living on unrefined carbohydrates. The distinctive soft stools of these Africans which are passed twice daily have been described by $H$. Dodd, ${ }^{2}$ who visited them in 1964, and we shall be surprised indeed if the transit times are not correspondingly illuminating.

It would seem to us that Dr. O. N. Manousos and others, in contending that the basic abnormality in diverticulosis lies in incoordinated colonic activity, puts the blame on the body, instead of-as set out in $\mathrm{Mr}$. Painter's letter-on a change in the food or on some other abnormality in the environment. And it is in this connexion that we believe that the differential incidences in the negro are of such great importance.We are, etc.,

\section{Fareham, \\ Hampshire. \\ G. D. Campbell.

$$
\begin{aligned}
& 1 \text { Morris, J. N., Lancet, 1941, 1, } 51 . \\
& 2 \text { Dodd, H., Lancet, 1964, 2, 910. }
\end{aligned}
$$

T. L. Cleave.

\section{Incidence of Diverticulosis}

Sir,-In my last 3,000 tabulated postmortem results at the (Royal) Adelaide Hospital between 1940 and 1948 (when I retired) there were 78 examples of diverticulosis of the colon-57 in men and 21 in women (there were about twice as many men a women). This shows a decidedly greater incidence in men. There was one woman of 31 and one man of 43 ; in males there were 6 out of 434 in their $50 \mathrm{~s} ; 21$ out of 555 in the $60 \mathrm{~s} ; 23$ out of 343 in the $70 \mathrm{~s}$; and 6 out of 90 over 80 . In women the respective figures were 2 in 217,11 in 249,4 in 145 , and 3 in 40 .

These results, about which there can be no question even if some instances were not recorded, were in a (then) almost pure British community. They differ markedly from those recorded by Dr. O. N. Manousos and others (23 September, p. 762) for the Oxford area, who found by radiological studies that $40 \%$ of people over 70 had diverticulosis. My figures are 36 examples in 589 persons over 70 , or about 1 in 16 . Those of us over 70 will now feel happier.

May I take this opportunity of calling attention to my tabulated results (in thousands) of 7,000 necropsies at the (Royal) Adelaide Hospital between 1920 and 1948. These were printed in the annual reports of that hospital under the title of "The Medical and Scientific Archives of the Adelaide Hospital." All pathological conditions, except trivialities, were recorded in the summary of each case, and this summary accompanied the tabulation. Thus it is easy to ascertain how many individuals had hypertrophied hearts or gallstones or melanosis of the colon or carcinoma of the lung, and what other lesions were also present in each case. These annual reports and medical archives contain a mine of information for the medical world to use if it knows of their existence and has access to them.-I am, etc.,

\section{University of Adelaide,
Australia.}

John B. Cleland.

\section{Preventing Dental Caries}

SIR,-Your leading article (3 February, p. 267) "Phosphates to Prevent Dental Caries" recalled to me the custom of the people of Barotseland in the Upper Zambesi, to whom I was medical officer long, long ago.

For them salt was scarcely available and they had no sugar. For flavouring, it was their custom to sprinkle their food, chiefly mealie meal or cassava and fish, very freely with wood ash, preferably from burned river weeds. Their physique was good and dental caries extremely rare. They cleaned their teeth occasionally, rubbing them with a piece of wood, and I think they sometimes used ash as tooth-powder. Dr. E. C. Wood, our Public Analyst, tells me that the ash would contain a high proportion of potassium and perhaps calcium phosphate. Calcium sucrose phosphate might be more potent for good.

My friends who have a strong objection to "chemicals" being added to their food or drinking-water would probably eat woodash with gusto and feed their children on it. Some of us might augment our incomes by selling the product of our garden bonfires if that is not unethical. The preliminary results of the long-term study being undertaken in Australia make one very hopeful that the scourge of dental caries may be reduced by inexpensive methods which can cause no qualms of conscience.-I am, etc.,

$$
\text { Paignton, Devon. IAN D. DicksoN. }
$$

\section{Varicose Ulcers and Use of Topical} Corticosteroids

Sir,-Some weeks ago Dr. Clifford D. Evans and others (25 November, p. 482) drew attention to the adverse effect of topical corticosteroid applications on gravitational ulcers. I have recently recognized another undesirable effect of these preparations, when used to suppress the eruption of rosacea. They do suppress the pustule formation, but the telangiectasia may be made much more prominent, presumably because the dermal collagen is thinned. When the corticosteroid applications are stopped a severe recurrence of the 